\title{
Acute Nephritis and Streptococcal Sore Throat: a Prospective Study in General Practice
}

\author{
P. M. HIGGINS, ${ }^{*}$ м.в., M.R.C.P.; B. A. ABBOTT,* м.B., B.CH., B.A.o.; P. M. JAMES,* M.B., CH.B.; \\ S. DILlON,* M.B., CH.B. ; P. J. MACMONAGLE,* M.B., в.CH.
}

Brit. med. F., 1965, 2, 1156-1160

The evidence linking acute nephritis and infection of the throat or skin with certain types of group A beta-haemolytic streptococci is of three kinds: (1) studies of streptococcal disease when acute nephritis was more prevalent than usual, (2) cultures from the throats of established cases of acute nephritis, and (3) serological studies of such cases for type-specific antibodies.

Examples of the first are the reports of Manser and Wilson (1952), Reed (1953), Kleinman (1954), Seigel et al. (1955), Stetson et al. (1955), and George et al. (1958). Studies of established cases of acute nephritis have been reported by Rammelkamp and Weaver (1953), Wertheim et al. (1953), Wilmers et al. (1954), Hardin et al. (1956), and Bernstein and Stillerman (1960). Two investigations on the production of type-specific antibodies are noteworthy-those of Cullhed et al. (1959) and of Earle and Jennings (1959). The strain most often found in association with acute nephritis is type 12, but types 4 , 25, and 49 are also thought to be nephritogenic.

The evidence provided by these varied reports is incomplete and open to objections. The epidemics studied may not reflect the experience of normal communities. Strains isolated from established cases of acute nephritis may differ from the original Infecting organisms, as reinfection with a different type is known to occur (Ravenswaay, 1944, Rantz et al., 1945). In assessing the significance of such isolations it is essential to know the prevalence of different types in the community from which the cases are drawn. There are, however, few reports on the relative incidence of different types in acute pharyngitis in normal populations; what evidence there is suggests that type 12 is widely prevalent (Siegel et al., 1961; Mitchell, 1962; Valkenburg et al., 1963).

Moreover, the literature abounds in anomalies. Acute nephritis is said to be twice as common in males (Seegal et al., 1935 ; Earle and Seegal, 1957), though there is no evidence that infection with "nephritogenic" types shows a similar sex incidence. Only a minority of those infected by type 12 streptococci actually develop acute nephritis, and the incidence following type 12 infections varies (Rammelkamp, 1957). Other types have been isolated from cases of acute nephritis (Wertheim et at., 1953 ; Goldsmith et al., 1958 ; Mitchell, 1962). Urinary abnormalities without other signs of renal disease, while commoner and more notable after type 12 infections, may also occur after infection with other types, or after non-streptococcal infections (Stetson et al., 1955).

Only one of the reports quoted was a prospective study, and this was carried out in a military camp where acute nephritis was already prevalent (Stetson et al., 1955). The only example of such a study in a normal community that we were able to find up to 1958 was reported by Rammelkamp et al. (1952) in a group of 60 families, and one other (Goslings et al., 1963) has since appeared.

We report here a prospective study in a normal community: in a small town and the neighbouring countryside, virtually the whole population of which is under our care. In 1959 this population numbered approximately 14,000 persons ; the study began on 28 January of that year and continued for 12 months.

- General Practitioners, Rugeley, Staffs.
The objects were: (1) to determine the prevalence of different types of streptococci found in association with acute sore throat, (2) to uncover cases developing acute nephritis or urinary abnormalities after streptococcal pharyngitis, and (3) to relate them to the type of Streptococcus pyogenes isolated at the patient's first attendance.

\section{Method}

All patients with symptoms or signs of sore throat were admitted to the study. The throat was swabbed when the patient was first seen, and specimens of urine were tested. After three months it became necessary to reduce the number of urine specimens tested, and patients were asked thereafter to send in one specimen when first seen, and a second three weeks later. For the first nine months information (including details of temperature and treatment) was recorded on special cards; recording was then simplified and such details were omitted.

Urines were tested by heat and acetic acid; if protein was found the urine was centrifuged and the deposit examined microscopically.

Throat swabs were sent by post to the Public Health Laboratory 10 miles $(16 \mathrm{~km}$.) away (usually arriving within 24 hours) and were sown on to horse-blood agar plates, which were incubated aerobically at $37^{\circ}$ C. for 24 hours. Subcultures of all Str. pyogenes isolations were sent to other centres for typing by both slide agglutination and precipitation techniques (Williams, 1958).

Previous experience had shown that it was futile to spend much effort in pursuing patients who failed to submit urine specimens. All were given printed instructions when first seen, and reminders were sent to those yielding Str. pyogenes.

Choice of treatment was left to the individual doctor. When penicillin was prescribed it was given orally, and usually for no more than four to five days.

\section{Results}

A total of 1,136 cases of sore throat were seen, an incidence of 81.2 cases per 1,000 of the population. In two a swab could not be taken, and in nine there was no record of the result of throat culture. There remained 1,125 cases of sore throat occurring in 1,005 patients, the youngest being 6 months old and the oldest 71 years. In all, 1,496 throat swabs were examined and 1,761 specimens of urine tested. Over twothirds of all cases had at least one urine test.

The number of cases recorded by the different doctors varied greatly-from a minimum of 61 to a maximum of 523. A few cases were known to have been missed.

\section{Bacteriological Results}

In $670(59.5 \%)$ cases culture of the throat swab revealed no pathogenic organisms. In $13(1.1 \%)$ cases Staphylococcus aureus was isolated in pure culture ; in 27 (2.4\%) streptococci 
of groups $\mathrm{C}$ and $\mathrm{G}$; in $59(5.2 \%)$ streptococci of groups other than $\mathrm{A}, \mathrm{C}$, or $\mathrm{G}$; and in $14(1.2 \%)$ a variety of pathogens including Streptococcus pneumoniae, Streptococcus viridans, Haemophilus influenzae, and Neisseria spp., all with moderate or heavy growths and often in pure culture.

In $342(30.4 \%)$ cases Str. pyogenes was found ; $133(39 \%)$ cases occurred in the 5-9 age group. The youngest patient was an infant of 12 months (type 12); the oldest was aged 69 $(5 / 27 / 44)$.

The isolation rates for individual doctors varied from $16 \%$ to $47 \%$.

Typing results on $311(91 \%)$ strains of Str. pyogenes isolated were available (Table I); one of these proved untypable. Fifteen $(4.4 \%)$ strains did not survive subculture or storage, and the records for $13(3.8 \%)$ were lost.

TABLE I.-Type Identification of Str. pyogenes Isolated from 311*

\begin{tabular}{|c|c|c|c|c|c|c|c|c|}
\hline \multirow{2}{*}{ Type } & \multicolumn{2}{|c|}{ Strain s } & \multirow{2}{*}{ Type } & \multicolumn{2}{|c|}{ Strains } & \multirow{2}{*}{ Type } & \multicolumn{2}{|c|}{ Strains } \\
\hline & No. & $\%$ & & No. & $\%$ & & No. & $\%$ \\
\hline $\begin{array}{c}\text { Untypable } \\
1 \\
2 \\
3 \\
4 \\
5 \text { (5/27/44) }\end{array}$ & $\begin{array}{r}1 \\
13 \\
4 \\
25 \\
62 \\
82\end{array}$ & $\begin{array}{r}0.3 \\
4 \cdot 2 \\
1.3 \\
8 \cdot 0 \\
19 \cdot 9 \\
26 \cdot 4\end{array}$ & $\begin{array}{l}(5 / 12 / 27 / 44) \\
6 \\
(8 / 25 / 19) \\
11 \\
12 \\
13\end{array}$ & $\begin{array}{r}2 \\
6 \\
8 \\
12 \\
82 \\
1\end{array}$ & $\begin{array}{r}0.6 \\
1.9 \\
2.6 \\
3.9 \\
26.4 \\
0.3\end{array}$ & $\begin{array}{l}14 \\
19 \\
22 \\
28 \\
48\end{array}$ & $\begin{array}{l}3 \\
2 \\
1 \\
6 \\
1\end{array}$ & $\begin{array}{l}1.0 \\
0.6 \\
0.3 \\
1.9 \\
0.3\end{array}$ \\
\hline
\end{tabular}

- Typing results were not available on 31 strains.

Fifteen different types were isolated during the year, but three predominated; $82(26.4 \%)$ strains agglutinated with antisera for $5 / 27 / 44,14(17 \%)$ of these giving a positive precipitin test with type 5 antisera ; $82(26.4 \%)$ strains were of type 12 ; and $62(19.9 \%)$ were of type 4 . There were 25 (8\%) isolations of type 3 , and $13(4.2 \%)$ isolations of type 1 . All types were scattered throughout the community.

While isolations of Str. pyogenes increased during the autumn, isolations of the three main types varied from month to month (Table II). Unlike other types, type 12 isolations did not fall off during the summer months (except for August, when many patients and some doctors were on holiday), though there was a drop in November, at a time when isolations of other types were on the increase.

Type 4, after four isolations in May (three of them in one estate), did not appear again until the autumn, and, when it did, was found in four widely scattered parts of the town.

TABLE II.-Cases Yielding Group A Streptococci. Isolations, by Month, for All Cases, and for Three Main Types

\begin{tabular}{l|r|r|r|r|r|r|r|r|r|r|r|r|r|r}
\hline Month: & $\left(\mathrm{J}^{*}\right)$ & $\mathrm{F}$ & $\mathbf{M}$ & $\mathrm{A}$ & $\mathrm{M}$ & $\mathrm{J}$ & $\mathrm{J}$ & $\mathrm{A}$ & $\mathrm{S}$ & $\mathrm{O}$ & $\mathrm{N}$ & $\mathrm{D}$ & $(\mathrm{Jt})$ & Total \\
\hline All cases & $(3)$ & 13 & $\mathbf{1 7}$ & $\mathbf{2 4}$ & $\mathbf{2 1}$ & $\mathbf{1 7}$ & $\mathbf{1 7}$ & $\mathbf{8}$ & $\mathbf{2 7}$ & $\mathbf{4 7}$ & 36 & 67 & $\mathbf{( 4 5 )}$ & 342 \\
\hline $\begin{array}{l}\text { Type 12 } \\
\text { Type 4 } \\
\text { 5/27/44 }\end{array}$ & 2 & 1 & 2 & 1 & 7 & 10 & 9 & 2 & 10 & 12 & 4 & 11 & 13 & 82 \\
\hline
\end{tabular}

- Only four days in January 1959.

+27 days in January 1960.
In 16 families (composed of 36 individual patients) the same type, and in another five families (11 patients) a typed and an untyped strain of Str. pyogenes were isolated from cases of sore throat occurring within two weeks of each other. No single type predominated in these family infections.

There was no evidence of a difference between the sexes in the incidence of either Str. pyogenes as a whole or of the three predominant types.

A higher proportion of types 4 and 12 were found in younger age groups than other types; $51 \%$ of the cases yielding type 4 and $43 \%$ of those yielding type 12 occurred in the 5-9 age group, as compared with $24 \%$ for all other strains of Str. pyogenes. Thirteen per cent. of isolations of both types were in children under 5 , as compared with $3 \%$ for all other strains.

During the time (January to September) when details of treatment were recorded half the cases associated with Str. pyogenes were given penicillin initially. In calculating attack rates it has been assumed that this proportion held good for the whole series.

One case of rheumatic fever was seen in a boy of 7 , following a sore throat yielding 5/27/44 streptococci (negative precipitin test for $M$ antigen), which was treated with aspirin.

A rash resembling that of scarlet fever was noted in 12 cases; five yielding $5 / 27 / 44$ streptococci, five type 4 , one type 11 , and one type 19.

No typical cases of glandular fever were seen during the year, but in September one patient was found to have an enlarged spleen. Blood smears from this patient and 11 others were examined at that time, and four showed cells resembling those of glandular fever in small numbers.

\section{Urine Analysis Results}

One patient with persistent proteinuria due to chronic pyelonephritis has been omitted from the analysis. In their first week of illness nine patients voided specimens of urine which gave a faint turbidity on boiling; but the presence of proteinuria was not confirmed in the laboratory, and these specimens were not examined microscopically. This particular urine test has therefore been ignored in each case. Five specimens were from patients who yielded Str. pyogenes and four from those whose throat swabs yielded no pathogenic organisms.

The results of all other urine tests within the first week and in the second to fourth weeks after sore throat are set out in Table III. The results for those cases which yielded no pathogens or pathogens other than Str. pyogenes did not differ significantly, and they have therefore been grouped together. Follow-up in these cases was less complete than in those yielding Str. pyogenes; $245(71 \%)$ of these had at least one urine test after the first week, but, as many patients did not produce specimens till several reminders had been sent, the of Throat Swabs

\begin{tabular}{|c|c|c|c|c|c|c|c|c|c|c|}
\hline \multicolumn{4}{|c|}{ Throat Swab Culture } & \multicolumn{7}{|c|}{ Urine Tests } \\
\hline \multirow{2}{*}{\multicolumn{4}{|c|}{ Organisms Isolated }} & \multirow{2}{*}{ No. of Isolations } & \multicolumn{2}{|c|}{ Patients Tested } & \multicolumn{2}{|c|}{ Proteinuria } & \multicolumn{2}{|c|}{ Proteinuria + R.B.C.s } \\
\hline & & & & & Week 1 & Weeks 2-4 & Week 1 & Weeks 2-4 & Week 1 & Weeks 2-4 \\
\hline $\begin{array}{ll} & \text { Group A } \\
\text { Type 12 } & \ldots \\
\text { Type 4 } & \ldots \\
\text { Other types* } & \ldots \\
\text { Not typed } & \ldots\end{array}$ & $\begin{array}{l}\text { reptc } \\
\because \\
\therefore \\
\therefore\end{array}$ & $\begin{array}{c}\text { occi } \\
\cdots \\
\cdots \\
\cdots\end{array}$ & $\begin{array}{l}\because \\
\because \\
\because\end{array}$ & $\begin{array}{l}82(26.4) \dagger \\
62(19.9) \dagger \\
167(53.7) \dagger \\
31\end{array}$ & $\begin{array}{r}57(69 \cdot 6) \\
42(67 \cdot 7) \\
116(69 \cdot 4) \\
24(77 \cdot 4)\end{array}$ & $\begin{array}{l}33(40 \cdot 2) \\
14(22 \cdot 6) \\
59(35 \cdot 3) \\
16(51 \cdot 6)\end{array}$ & $\begin{array}{c}6(10 \cdot 5) \\
3(7 \cdot 1) \\
15(12 \cdot 9) \\
3(12 \cdot 5)\end{array}$ & $\begin{array}{l}4(12 \cdot 1) \\
2(14 \cdot 3) \\
8(13 \cdot 5) \\
1(6 \cdot 2)\end{array}$ & $\begin{array}{l}2(3 \cdot 5) \\
1(2 \cdot 4) \\
0\left(-\frac{1}{1}\right) \\
1(4 \cdot 2)\end{array}$ & $\begin{array}{l}4(12 \cdot 1) \\
2(14 \cdot 3) \\
1(1 \cdot 7) \\
1(6 \cdot 2)\end{array}$ \\
\hline Total .. & . & . & . & $342(30.4) \ddagger$ & $239(69 \cdot 9)$ & $122(35 \cdot 7)$ & $27(11 \cdot 3)$ & $15(12 \cdot 3)$ & $4(1 \cdot 7)$ & $8(6 \cdot 5)$ \\
\hline $\begin{array}{l}\text { Other pathogens } \\
\text { No pathogens }\end{array}$ & & . & $\cdots$ & $783(69 \cdot 5)$ & $494(63 \cdot 1)$ & $179(22 \cdot 9)$ & $37(7 \cdot 5)$ & $9(5 \cdot 0)$ & $5(1 \cdot 0)$ & $1(0.6)$ \\
\hline Total patients.. & . & . & . & 1,125 & $733(65 \cdot 1)$ & $301(26 \cdot 8)$ & $64(8 \cdot 7)$ & $24(7 \cdot 9)$ & $9(1 \cdot 2)$ & $9(2 \cdot 9)$ \\
\hline
\end{tabular}


results do not appear in the table. Their inclusion would not substantially affect the findings.

As typing results were not known until after the end of the study, there was no bias in the follow-up of different types within the Str. pyogenes series. The differences between those cases associated with type 4 and those yielding an untyped streptococcus group A were due to the fact that the latter predominated in the early part of the year, when more urines were examined in each case. Towards the end of the year, when type 4 isolations were at their peak, the single follow-up urine was often not produced until after the fourth week.

In the first week of observation $239(69.9 \%)$ of cases yielding Str. pyogenes had at least one urine test ; in $27(11.3 \%)$ proteinuria was found, and in four $(1.7 \%)$ of these red cells were noted in the urine. One of these four patients was in the series yielding an untyped streptococcus; two, both of whom had other $s$ igns of acute nephritis, were in the series yielding type 12 , and one was in the series yielding type 4 . Thus $3.5 \%$ of the cases associated with type 12 and $2.4 \%$ of those associated with type 4 were found to have haematuria; no case with haematuria was found among the 116 tested in the series yielding other types.

Among those cases yielding other pathogens or no pathogens, 494 were tested in the first week, and in $37(7.5 \%)$ proteinuria was found. In $5(1.0 \%)$ red cells were noted in the urine; three were adult females (one had pyelonephritis, one had rheumatic heart disease, and one had frequency and dysuria). The fourth patient, a boy of 2 years, excreted an occasional red cell plus numerous granular casts during the acute stage of his pharyngitis. (A similar case of brief cylindruria and proteinuria, but without red cells, occurred in the Type 12 series.) The fifth patient, a girl of 11 , whose throat yielded a mixed culture of Staph. aureus and beta-haemolytic streptococci not of group A, C, or G, excreted red cells on the fifth day of her illness.

During the second, third, and fourth weeks only $9(5.0 \%)$ cases in this whole group were found to have proteinuria, and in only one $(0.6 \%)$ were red cells noted. This patient was a woman of 34 who may have had cystitis (see Table IV).

In contrast, $15(12.3 \%)$ of the series yielding Str. pyogenes were found to have proteinuria. In $8(6.5 \%)$ of the 15 patients red cells were noted ; $4(12.1 \%)$ in the series yielding type 12 , $2(14.3 \%)$ in the series yielding type $4,1(6.2 \%)$ yielding an untyped streptococcus, and 1 (1.7\%) yielding another type. The differences between the groups yielding type 12 and type 4 and those yielding other types are statistically significant $(\mathbf{P}<0.05)$, but the figures in the two former groups include cases which were found to have haematuria in the first week and which were therefore followed into subsequent weeks. If only new cases found to have haematuria are considered, differences remain, but they lose statistical significance: 2 $(6.4 \%)$ of the 31 patients yielding type 12 tested and $1(7.7 \%)$ of the 13 yielding type 4 were found to have haematuria in the second to fourth weeks, as compared with $1(1.7 \%)$ out of 59 yielding other types. However, the clinical picture of the one case with haematuria in the group yielding other types suggested previous renal disease (Table IV) ; a girl of 14, she had heavy proteinuria with an orthostatic reaction; proteinuria recurred subsequently, accompanied by a few red cells. One similar case (which does not appear in the tables) of recurrent proteinuria in a boy of 14 followed a sore throat yielding $5 / 27 / 44$ streptococci; a few granular casts and an occasional red cell were noted in one urine eight weeks later. In the one case in the series with no pathogens on throat culture, haematuria was probably due to cystitis.

Two patients yielding type 12 had oedema, oliguria, and granular casts as well as red cells ; one (J. J.) appeared to be a clear instance of acute nephritis following a sore throat, but in the other (J.B.) evidence of nephritis was found simultaneously with her sore throat; she had been ill for over a week and the antistreptolysin $\mathrm{O}$ titre was over 800 units $/ \mathrm{ml}$. when she was first seen. Only one other patient (M. C.) may have had acute nephritis, following a sore throat yielding type 4 . A midwife of 59 , she gave a history of transient oedema, oliguria, dyspnoea, and of passing "khaki" urine a week after her sore throat, but this was not observed at first-hand. She was later found to have carcinoma of the lung.

Staph. aureus was isolated in pure culture in 13 cases and in mixed culture of heavy or moderate growth, together with another pathogen, in 10 others; in six the other pathogen was Str. pyogenes, and these patients have been analysed in the appropriate Str. pyogenes series. In 17 of these 23 patients the urine was tested, and in five protein was found (in four within four weeks and in one after four weeks). The concentration of protein in each exceeded $15 \mathrm{mg} . / 100 \mathrm{ml}$, whereas in three-quarters of all those with proteinuria (with or without other abnormalities) in the group yielding no pathogen and in just over one-third of those in the whole series yielding Str. pyogenes of all types proteinuria never exceeded $15 \mathrm{mg} . / 100 \mathrm{ml}$. in single specimens at any time.

During the year four patients (all males) presented with acute nephritis outside the study population; in three the first symptom was haematuria. One had otitis media, and type 1 streptococci were isolated from the ear; two others yielded no streptococci but the antistreptolysin $\mathrm{O}$ titre was $460 \mathrm{units} / \mathrm{ml}$. or higher in each; the fourth was admitted to hospital. One other patient, also male, may have been a case of acute nephritis at a late stage, but was probably a case of chronic nephritis: throat culture yielded type 3 streptococci.

\section{Discussion}

The aim of this study was to investigate all patients with sore throat seen by a doctor in this compact community of approx:mately 14,000 persons during the year, and to define a group yielding Str. pyogenes on throat culture and to follow up all patients so as to uncover any who developed urinary abnormalities.

Notable variations were found between the doctors in the numbers recorded and in the isolation rates of Str. pyogenes. The discrepancies in isolation rates were no doubt due to differences in swabbing techniques, and perhaps to some selection of cases, but the differences in numbers of cases recorded appeared to be largely due to sociological differences in the populations each doctor looked after. It is known that a few

TABlE IV.-Patients with Microscopical Haematuria after the First Week

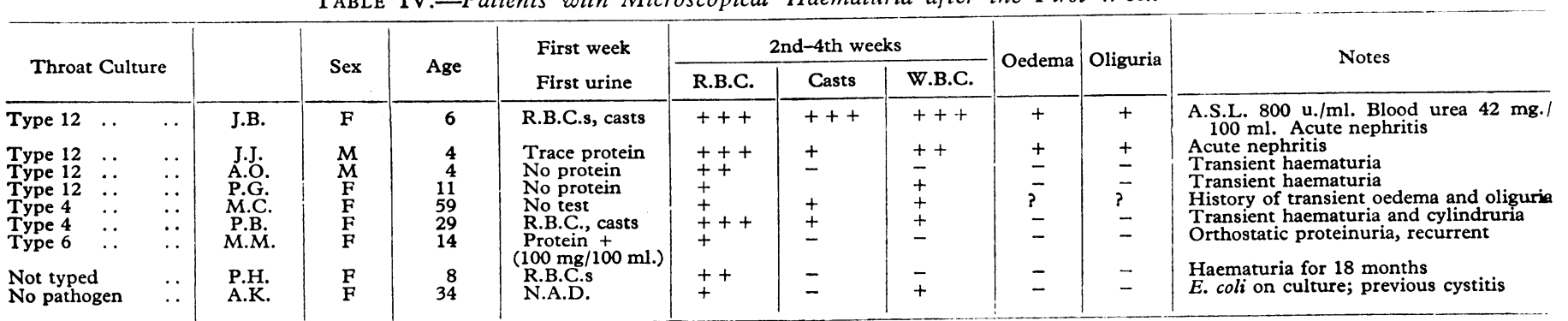


cases were missed but the majority were admitted to the study; the patient-consulting rate of 72.6 per 1,000 population compares with a figure of 66.3 patients consulting for acute tonsillitis, pharyngitis, and streptococcal sore throat combined, derived from a study of morbidity in general practice (General Register Office, 1958).

Although higher isolation rates of group A streptococci have been achieved (Chapple et al., 1956; Holmes and Williams, 1958 ; Brumfitt et al., 1959), our figure of $30.4 \%$ compares with other reports (Cornfeld et al., 1958 ; Siegel et al., 1961). The use of the slide agglutination reaction for $T$ antigens, together with the precipitation test for $M$ antigen, enabled all but one strain of those submitted to typing to be typed. Fifteen different types were found but three predominated: type 12, type 4 , and strains agglutinating with the sera for 5/27/44.

There was little evidence that spread within family groups was a notable feature of these infections.

Two unequivocal cases of acute nephritis were encountered in the study population; one followed on a sore throat yielding type 12 streptococci not treated with penicillin-giving an attack rate of 1.2 per 100 cases associated with type 12 or 2.4 per 100 cases estimated not to have received penicillin. The other, whose throat culture also yielded type 12, had acute nephritis when first seen, and the relationship of the organism to the urinary findings is therefore less clear. One other patient may have had acute nephritis following a sore throat yielding type 4 streptococci treated with penicillin-an attack rate of 1.6 per 100 cases. In the second to fourth weeks $12 \%$ of all cases tested in the group yielding type 12, and $14 \%$ of those yielding type 4 , were found to have haematuria as against $1.7 \%$ of those yielding other types and $0.6 \%$ of those from whose throat Str. pyogenes was not cultured.

These attack rates for acute nephritis and the figures for the incidence of haematuria are based on small numbers, but they do provide some measure of the expectation of finding similar cases after sore throats yielding other types of streptococci. Although the data presented in the study show that proteinuria and haematuria of short duration after the first week only followed sore throats yielding type 12 or type 4 , it must be noted that these types accounted for $46 \%$ of all typed strains isolated. Certainly no similar case was found out of 25 tested in the second to fourth weeks in the group yielding 5/27/44 streptococci, but many more cases would be required to show that the less frequently isolated types could not cause nephritis. The 10 patients tested in the second to fourth weeks in the group yielding type 3 might be expected to give rise to one case with haematuria, and the seven tested in the group yielding type 1 to none. Each of these types was in fact found in association with a case of certain (type 1) or possible (type 3) acute nephritis, though these were outside the study population. Goldsmith et al. (1958) reported a family outbreak of acute nephritis associated with type 1 , and a similar case was seen in a previous study (Higgins, 1965). Isolations from established cases of acute nephritis have as much (or as little) relevance to the problem of nephritogenic capacity in such instances as in the case of type 12, and the relative frequency of the isolation of different types must be critically related to their different prevalences. On the other hand, a food-borne epidemic due to type 1 and involving 250 patients has been reported in which no cases of acute nephritis were observed (Rantz et al., 1945).

Altogether six patients with unequivocal acute nephritis were seen during the year-an incidence of 0.4 case per 1,000 of population. A study of morbidity in general practice (General Register Office, 1958) gives a rate of 0.5 patient consulting per 1,000 population for nephritis and nephrosis combined, but this is a measure of prevalence, including known as well as new cases. Experience during the year suggested that to be on the look-out for renal disease was to be half-way to finding it.

The sex ratios of the group that entered the study differed from that encountered outside it. Of the two certain cases and one possible case of acute nephritis found in the study population two were female, and if all eight cases within the group A series found to have red cells in the urine during the second to fourth weeks are considered only two were male. On the other hand, the four patients outside the study who were found to have acute nephritis were all males; three presented with haematuria. An obvious explanation is that all patients in the study had an equal chance of a urine test, whereas the discovery of renal disease in the others depended upon the patient noticing, and reporting, an abnormality. The known excess of males presenting with acute nephritis may therefore depend upon the greater likelihood that they will do so. If this is true, it follows that at least half the cases of acute nephritis in females are missed.

All serious renal abnormalities in the study population were uncovered by routine urine examinations, and it is likely that all but two patients would have been missed without such tests.

\section{Summary}

Results of a prospective study of acute pharyngitis associated with Streptococcus pyogenes, and renal complications, in a compact community of approximately 14,000 people are reported.

A total of 1,125 cases of sore throat were studied: 342 yielded cultures of Str. pyogenes, $91 \%$ of which were typed. Three types predominated: type 12, type 4, and strains agglutinating with antisera for types $5 / 27 / 44$.

Types 12 and 4 together accounted for $46 \%$ of the 311 strains typed.

Seasonal variations in the prevalence of types 12 and 4 and a higher incidence of these types among younger children were noted.

Two definite cases of acute nephritis were found, both in the series yielding type 12 ; one other possible case occurred in the series yielding type 4.

In the second to fourth weeks after a sore throat a total of $4(12.1 \%)$ cases with haematuria were found in the series yielding type 12 , and $2(14.3 \%)$ in the series yielding type 4 ; only 1 case $(1.7 \%)$ was seen in the series yielding other types, and $1(0.6 \%)$ in the group yielding no pathogens.

The difficulty of proving that any single type is not nephritogenic is discussed:

Evidence is presented suggesting that the belief that acute nephritis is commoner in males may be fallacious.

This work was carried out in conjunction with the Public Health Laboratory Service; to the Director of the Laboratory in Stafford, Dr. E. Mackay-Scollay, we owe particular thanks for his encouragement and assistance throughout. Thanks are due also to Professor R. E. O. Williams and Dr. M. T. Parker, who typed the strains of streptococci, and who, together with Professor M. L. Rosenheim, gave us much helpful advice. We are grateful also to Miss $\mathbf{M}$. Wall, Statistician to the Birmingham Regional Hospital Board, for statistical advice and to Drs. T. A. McLintock, R. Rouse, and A. Lower for their help during the study.

\section{REFERENCES}

Bernstein, S. H., and Stillerman, M. (1960). Ann. intern. Med., 52, 1026. Brumfitt, W., O'Grady, F., and Slater, J. D. H. (1959). Lancet, 2, 419. Chapple, P.' A. L., Franklin, L. M., Paulett, J. D., Tuckman, B., Woodall, J. T., Tomlinson, A. J. H., and McDonald, J. C. C. (1956). Brit. med. F., 1, 705.

Cornfeld, D., Werner, G., Weaver, R., Bellows, M. T., and Hubbard, J. P. (1958). Ann. intern. Med., 49, 1305.

Cullhed, I., Juhlin, I., Werner, I., and Laurell, G. (1959). Acta med. scand., 165, 17.

Earle, D. P., and Jennings, R. B. (1959). Ann. intern. Med., 51, 851. Earle, and Seegal, D. (1957). f. chron. Dis., 5, 3.

General Register Office (1958). Studies on Medical and Population Sublects No. 14. Morbidity Statistics from General Practice, vol. 1. H.M.S.O., London. 
George, J. T. A., McDonald, J. C., Payne, D. J. H., and Slade, D. A., (1958). Brit. med. f., 2, 1381.

Goldsmith, H. J., Cowan, M. A., and Gooder, E. (1958). Lancet, 2, 674.

Goldsmith, H. J., Cowan, M. A., and Gooder, E. (1958). Lancet, 2, 674. (1963) W. R. O., Valkenburg, H. A., Bots,

Hardin, R. A., Quinn, R. W., and Avery, R. C. (1956). F. infect. Dis., 99, 84.

Higgins, P. M. (1965). 7. Coll. gen. Practit., 9, 136.

Holmes, M. C., and Williams, R. E. O. (1958). 'f. Hyg. (Camb.), 56, 43.

Kleinman, H. (1954). Minn. Med., 37, 479.

Manser, R. W. E., and Wilson, M. M.'(1952). Med. F. Aust., 2, 339.

Mitchell, E. S. (1962). 7. clin. Path., 15, 231.

Rammelkamp, C. H. (1957). Harvey Lectures, 1955-6, Series 51, N.Y. - and Weaver, R. S. (1953). 7. clin. Invest., 32, 345.

Ran and Dingle, J. H. (1952). Trans Ass. Amer. Phycns, 65, 168

Rantz, L. A., Spink, W. W., and Boisvert, P. J. (1945). Arch. intern. Med., 76, 278.
Ravenswaay, A. C. van (1944). f. Amer. med. Ass., 126, 486.

Reed, R. W. (1953). Canad. med. Ass. f., 68, 448.

Seegal, D., Seegal, B. C., and Lyttle, J. D. (1935). F. Amer. med. Ass., $105,17$.

Siegel, A. $\dot{\text { C. }, ~ J o h n s o n, ~ E . ~ E ., ~ a n d ~ S t o l l e r m a n, ~ G . ~ H . ~(1961) . ~ N e w ~}$

Engl. 7. Med., 265, 559. 33.

Stetson, C. A., Rammelkamp, C. H., Krause, R. M., Kohen, R. J., and Perry, W. D. (1955). Medicine (Baltimore), 34, 431.

Valkenburg, H. A., Goslings, W. R. O., Bots, A. W., de Moor, C. E., and Lorrier, J. C. (1963). New Engl. Ұ. Med., 268, 694

Wertheim, A. R., Lyttle, J. D., Loeb, E. N., Earle, D. P., Seegal, B. C.,

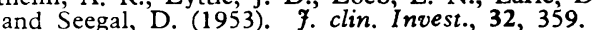

Williams, R. E. O. (1958). Bull. Wld Hlth Org., 19, 153.

Wilmers, M. J., Cunliffe, A. C., and Williams, R. E. O. (1954). Lancet, 2,17 .

\title{
Fluoresceinretinography: Exudates and Microaneurysms
}

\author{
F. SKOVBORG,* M.D. ; E. LAURITZEN,* M.D.
}

Brit. med. F., 1965, 2, 1160-1162

Novotny and Alvis's (1961) technique for investigation of the retina by intravenously injected fluorescein has opened up new possibilities for examining the vessels in different pathological conditions.

Fluoresceinretinography gives an impression of the permeability of the vessels, and in proliferative retinopathy many more new vessels are revealed than by ordinary ophthalmoscopy. A bright fluorescence is seen in the cotton-wool exudates, but not in the waxy exudates (Dollery et al., 1962 ; Hodge and Dollery, 1964 ; Scott et al., 1964 ; Skovborg and Lauritzen, 1964).

Dollery et al. (1962), Hodge and Dollery (1964), and Scott et al. (1964) state that fluoresceinretinography reveals many more microaneurysms in the retina among diabetics and hypertensive patients than can be seen by ordinary ophthalmoscopy.

From our results and the study of other papers we conclude that most of the small fluorescent dots are not microaneurysms, but are probably small exudations of the same type as the cotton-wool exudates. This paper is primarily concerned with the diagnostic problems of differentiating by fluoresceinretinography between microaneurysms and small cotton-wool exudates.

\section{Method}

The method used was that described by Novotny and Alvis (1961) with Dollery et al.'s (1962) modifications. Instead of Ilford 717 we used Fluorodak (Kodak) film (Jensen, personal communication) because this film is especially sensitive to fluorescent light.

Fluoresceinretinography has been carried out on 110 diabetics. Our main results are in agreement with other publications (Dollery et al., 1962 ; Hodge and Dollery, 1964 ; Scott et al., 1964).

Many of the cotton-wool exudates are loaded with fluorescein. Fig. 1 demonstrates such an example. There is a vigorous fluorescing circular area, which appeared in the arteriolar phase. At the same place on the colour print a cotton-wool exudate was seen.

Fig 2 demonstrates a single fluorescent dot. At exactly the same spot on the colour print there was a small exudate.

* Hvidøre Hospital, Klampenborg, Denmark.
In Fig. $3 a$ the fluorescein picture shows many more fluorescent dots without corresponding blood dots on the colour photograph (reproduced as Fig. 3b). Fig. $3 c$ shows the same area of retina two months later. Some of the fluorescent dots that were seen earlier cannot now be identified.

\section{Discussion}

As Fig. 3 demonstrates, fluoresceinretinography reveals many more fluorescent dots than correspond to the blood dots on the colour pictures. This has been previously shown by other authors (Novotny and Alvis, 1961 ; Dollery et al., 1962 ; Scott et al., 1964). These authors state that these fluorescent dots are microaneurysms filled with fluorescein. Such fluorescein-filled microaneurysms have also been observed in hypertensive patients without diabetes, according to Hodge and Dollery (1964).

It is possible that the fluorescent dots which can be identified with blood dots are microaneurysms, but on the other hand it is also possible that the fluorescein may have leaked out of the vessel at the point where the haemorrhage occurred, and the fluorescent dot thus represents a small haemorrhage and not a microaneurysm.

Most of the fluorescent dots cannot be identified with blood dots on the colour pictures, and there is no proof that these dots are microaneurysms. However, there are some characteristics which indicate that at least some of the fluorescent dots are microaneurysms-they all have the same dimension as the blood dots. Some of them seem to connect with the vessels. Furthermore some of them appear and disappear simultaneously with the filling and clearing of fluorescein in the vessels.

The last group may indicate microaneurysms with open connexion with the vessels. Fig. 1, however, demonstrates an example of a cotton-wool exudate where the fluorescein-filling took place very quickly-namely, in the arteriolar phase.

Fig. 2 shows a fluorescein dot of the same size as a blood dot, but this fluorescein dot could be identified with a nearly invisible small exudate. Moreover, it appeared and disappeared simultaneously with the filling and clearing of fluorescein in the vessels. Scott et al. (1964) have made a similar observation, and, according to Friedenwald (1950), 